\title{
Terminalia Chebulanin Attenuates Psoriatic Skin Lesion via Regulation of Heme Oxygenase-1
}

\author{
Jingang An ${ }^{\mathrm{a}}$ Tian Li ${ }^{b}$ Yingying Dong ${ }^{\mathrm{a}}$ Zhengxiao $\mathrm{Li}^{\mathrm{a}}$ Jia Huo \\ aDepartment of Dermatology, The Second Affiliated Hospital, School of Medicine, Xi'an Jiaotong \\ University, Xi'an, 'Department of Dermatology, Xijing Hospital, Fourth Military Medical University, Xi'an, \\ China
}

\section{Key Words}

Terminalia chebulanin • Psoriasis • Heme oxygenase-1 $\bullet$ NF-kB $・$ Inflammation

\begin{abstract}
Background/Aims: Psoriasis is one of the most common inflammatory skin disorders, affecting $3 \%$ of the general population. Terminalia chebulanin (TC) is a polyphenolic compound that possesses antioxidant and anti-inflammatory activities. The current study was designed to investigate the effect of TC on psoriatic lesions. Methods: We examined the protective effect of TC against psoriatic lesions in mice and keratinocyte proliferation in $\mathrm{HaCaT}$ cells. Results: We found that TC exhibited potent anti-psoriatic activities, as evidenced by improvement of erythema and scaling scores, decrease of epidermal, ear and skinfold thickening, decrease of tumor necrosis factor $\alpha$ (TNF $\alpha$ ), interleukin (IL)-17A, IL-23 and matrix metalloproteinase (MMP)-9 expression, and decrease of TBARS content and increase of GSH content in IMQtreated mice, and decrease of keratinocyte proliferation, TNF $\alpha$, IL-17A and IL-23 expression, and ROS level in M5-treated cells. All those effects induced by TC were inhibited by zinc protoporphyrin IX (ZnPP), an inhibitor of heme oxygenase (HO)-1, indicating that HO-1 was responsible the anti-psoriatic effect of TC. Moreover, TC inhibited the upregulation of p65 NF-kB under in vitro psoriatic condition. ZnPP suppressed TC-induced inhibition of p65 NF$\mathrm{KB}$ expression. Overexpression of p65 NF- $\mathrm{kB}$ significantly suppressed TC-induced decrease of TNF $\alpha$, IL-17A and IL-23 expression and keratinocyte proliferation, indicating that HO-1mediated downregulation of NF-KB was involved in the anti-psoriatic effect of TC. Conclusions: The data demonstrate that TC may serve as a potential therapeutic option for psoriatic patients.

\section{Introduction}

Psoriasis is one of the most common inflammatory skin disorders, affecting 3\% of the general population [1]. Psoriasis is a result of the interaction of genetic predisposition and external stimuli including stress, infection, trauma, and drugs [2-4]. This disease is characterized by a series of linked cellular changes in the skin, including hyperproliferative 


\section{Cellular Physiology Cell Physiol Biochem 2016;39:531-543 \begin{tabular}{c|c|c|} 
DOI: 10.1159/000445645 & $\begin{array}{l}\text { O 2016 The Author(s). Published by S. Karger AG, Basel } \\
\text { wwww.karger.com/cpb }\end{array}$
\end{tabular} \\ An et al.: Terminalia Chebulanin Ameliorates Psoriasis}

keratinocytes, parakeratosis, hyperkeratosis, and infiltration of inflammatory leukocytes into the dermis and epidermis, resulting in a thickened epidermis $[5,6]$. The mechanism of psoriasis is still not completely understood. It is urgently needed to explore the molecular mechanisms underlying the pathogenesis of psoriasis and to identify novel treatment for this disease [7].

Although the exact mechanism of psoriasis is unclear, inflammation and enhanced proliferation of keratinocytes are considered to be the key events in the development of psoriasis. Systemic low-grade inflammation is a hallmark of psoriasis [8-10]. The enhanced proliferation of lesional keratinocytes in the psoriatic skin area results in thickened epidermis [11]. As a traditional folk medicine, terminalia chebula retzius has been widely used in Asian countries for its antioxidant [12], anti-inflammatory [13], anti-bacterial activities. Researchers have isolated three polyphenolic compounds from the fruits of terminalia chebula retzius, including chebulagic acid, chebulanin, and chebulinic acid [14, 15]. Zhao et al. have found that terminalia chebulanin (TC) functions as an anti-inflammatory agent in lipopolysaccharide-stimulated RAW 264.7 cells and in collagen-induced arthritis in a mice model [16]. Moreover, terminalia chebula was shown to attenuate DMBA/croton oil-induced oxidative stress and inflammation in skin of Swiss albino mouse [17]. However, whether TC could attenuate psoriatic inflammation and skin lesions is unknown.

The present study was designed to examine the effect of TC on psoriatic inflammation and skin lesions and to elucidate the possible mechanisms. The results showed that TC exhibited potent anti-psoriatic effects via heme oxygenase (HO)-1-mediated inhibition of oxidative stress and NF- $\mathrm{KB}$ and the subsequent suppression inflammation and keratinocyte proliferation.

\section{Materials and Methods}

\section{Animals and Ethical Statement}

Sixty male BALBc mice (6-8 week old) were obtained from Experimental Animal Centre of Xi'an Jiaotong University. Mice were kept in individual cages and the environment was at constant temperature and humidity on 12-hour light/dark cycles. During the whole experimental period, the animals had free access to unlimited amounts of water and food. Animals were treated in accordance with the guidelines for the Care and Use of Laboratory Animals and the principles presented by Xi'an Jiaotong University and all experimental procedures were conducted in accordance with the guidelines of the Animal Experiments Inspectorate.

\section{Animal treatment}

The mice were randomly allocated into 4 groups ( $\mathrm{n}=15$ ); Control group, imiquimod (IMQ) group, TC group, and TC + zinc protoporphyrin IX (ZnPP) group. The mice in IMQ TC and TC + ZnPP groups received a daily topical dose of $62.5 \mathrm{mg}$ and $5 \mathrm{mg}$ of commercial IMQ cream (Aldara 5\%; MEDA Pharma, Germany) on the shaved back and right ear respectively for 7 consecutive days, as described previously [18-20]. The mice wore plastic collars to avoid licking IMQ on the skin. Mice in Control group were given equal dose of vehicle cream (Vaseline Lanette cream; Fagron). Mice in TC and TC + ZnPP groups were intragastrically administered with $50 \mathrm{mg} / \mathrm{kg}$ TC (ShangHai PureOne Biotechnology, China). Our preliminary experiments have shown that TC may induce liver injury when the dose was higher than $50 \mathrm{mg} / \mathrm{kg}$ (Table 1). Thus, in the present study, we administrated the mice with $50 \mathrm{mg} / \mathrm{kg}$ TC. Mice in TC + ZnPP groups were also intraperitoneally injected with $10 \mathrm{mg} / \mathrm{kg}$ ZnPP.

The backs of those mice were shaved and the mice were allowed 4 days of acclimatization before the experimental procedures. On days 0, 2, 4 and 7, the severity of the psoriasis-like skin lesion was evaluated using the Psoriasis Area Severity Index (PASI). Each mouse was assigned with a score of $0-4$ (0, none; 1 , mild; 2 , moderate; 3 , severe; 4 , very severe). Moreover, the thickness of the right ear fold (day 7) and the skinfold on the back (day 7) was measured using a digital micrometer (Helios, China). After the experiment, mice were euthanized and the shaved area of skin on their backs was immediately excised and collected. Part of the lesional skin was fixed for histological analysis. Photomicrographs of H\&E-stained epidermal 


\section{Cellular Physiology Cell Physiol Biochem 2016;39:531-543 \begin{tabular}{ll|l} 
DOI: 10.1159/000445645 & $\begin{array}{l}\text { O 2016 The Author(s). Published by S. Karger AG, Basel } \\
\text { www.karger.com/cpb }\end{array}$ \\
\cline { 2 - 3 }
\end{tabular}}

An et al.: Terminalia Chebulanin Ameliorates Psoriasis

Table 1. Effect of TC on profiles of liver enzymes in serum in mice. Mice were treated with 50-100 $\mathrm{mg} / \mathrm{kg} /$ day TC for one week. ALT, alanine transaminase; AST, aspartate transaminase; ALP, alkaline phosphatase. Results were expressed as means \pm SEM. $* \mathrm{p}<0.05$, compared with Control

\begin{tabular}{llll}
\hline Group & ALT (U/L) & AST (U/L) & ALP (U/L) \\
\hline Control & $75 \pm 8.7$ & $65 \pm 10.1$ & $109 \pm 11.5$ \\
$50 \mathrm{mg} / \mathrm{kg} \mathrm{TC}$ & $77 \pm 9.8$ & $66 \pm 11.2$ & $108 \pm 10.7$ \\
$75 \mathrm{mg} / \mathrm{kg} \mathrm{TC}$ & $85 \pm 12.1$ & $83 \pm 9.6^{*}$ & $116 \pm 6.9$ \\
$100 \mathrm{mg} / \mathrm{kg} \mathrm{TC}$ & $94 \pm 6.8^{*}$ & $97 \pm 10.4^{*}$ & $136 \pm 9.7^{*}$ \\
\hline
\end{tabular}

skin sections were captured using an Olympus microscope and thickness from basement membrane to the start of the stratum corneum was measured using Image J software. The remaining lesional skin was quickly frozen in liquid nitrogen and stored at $-80 \mathrm{C}^{\circ}$ for further analysis.

\section{Cell culture and transfection}

Human HaCaT cell line (keratinocytes) was purchased from the American Type Culture Collection (ATCC, Manassas, USA). Cells were cultured in high glucose Dulbecco's modified Eagle's medium (DMEM; Gibco, Grand Island, NY, USA) containing 10\% fetal bovine serum (Gibco) and penicillin (100 U/mL)/ streptomycin $(100 \mu \mathrm{g} / \mathrm{mL})$. Cells were maintained in a humidified atmosphere of $5 \% \mathrm{CO}_{2}$ at $37^{\circ} \mathrm{C}$. $\mathrm{M} 5$ cocktail (interleukin (IL)-1 $\alpha$, IL-17A, IL-22, Oncostatin $M$ and TNF $\alpha$, each at $10 \mathrm{ng} / \mathrm{ml}$ ) was used to induce psoriasis-like inflammation in HaCaT cells $[16,21]$. Cells were incubated with $10 \mu \mathrm{g} / \mathrm{ml} \mathrm{TC}$ for $2 \mathrm{~h}$ and then exposed to M5 for 2 days with the presence of TC. Cells were transfected with $100 \mathrm{ng}$ NF- $\mathrm{kB}$ plasmids or empty plasmids according to the manufacturer's protocols. $48 \mathrm{~h}$ after the transfection, cells were incubated with $10 \mu \mathrm{g} / \mathrm{ml}$ TC for $2 \mathrm{~h}$ and then exposed to M5 for 2 days with the presence of TC.

\section{H\&E staining}

Part of lesional skin of the back was fixed and H\&E staining was performed. Sections were observed and images were captured using an Olympus microscope.

\section{Cell proliferation}

$5 \times 10^{3} \mathrm{HaCaT}$ cells were plated in a well of 96-well plates. After the treatment, cell proliferation was determined by Cell Counting Kit-8 (Sigma Aldrich, USA) according to the manufacturer's instructions. The absorbance was measured using a microreader (BIORAD, USA).

\section{Determination of proinflammatory cytokines}

Serum and skin proinflammatory cytokines (TNF $\alpha$, IL-17A and IL-23) were determined using ELISA plates according to manufacturer's protocols (R\&D Systems, USA).

\section{Evaluation of oxidative stress}

Skin thiobarbituric acid reactive substances (TBARS) and glutathione (GSH) levels were measured using commercial kits according to manufacturer's protocols (Nanjing Jiancheng, China). Intracellular reactive oxygen species (ROS) was determined by $\mathrm{H}_{2}$ DCF-DA fluorescent probe (Invitrogen, Carlsbad, CA, USA). Briefly, after the treatment, cells were collected and $1 \times 10^{6}$ cells were incubated with $5 \mu \mathrm{M}$ of $\mathrm{H}_{2} \mathrm{DCF}-$ DA for $30 \mathrm{~min}$ at $37^{\circ} \mathrm{C}$ in dark. Percentage of positive cells was analyzed by flow cytometry and results were expressed as percentage of Control. ROS level was also measured by dihydroethidium (DHE) staining. After the treatment, cells were incubated with $10 \mu \mathrm{M}$ DHE for $15 \mathrm{~min}$ at $37^{\circ} \mathrm{C}$ in dark. Then, fluorescence was observed under a confocal microscope.

\section{Real-time PCR}

Total RNA was isolated from tissues and cells according to the manufacturer's instructions (TaKaRa). The concentration of total RNA was determined by spectrophotometry. Then, 500 ng RNA was reversetranscribed to cDNA using a cDNA synthesis kit (TaKaRa). The samples were analyzed by RT-PCR using the BIORAD System for quantitative evaluation. One microliter of cDNA was amplified with SYBR Premix Ex Taq (TaKaRa). Cycle conditions were as follows: initial denaturation at $95^{\circ} \mathrm{C}$ for $15 \mathrm{~min}$ followed by 40 cycles of denaturation at $95^{\circ} \mathrm{C}$ for $30 \mathrm{~s}$, annealing at $59^{\circ} \mathrm{C}$ for $30 \mathrm{~s}$, extension at $72^{\circ} \mathrm{C}$ for $30 \mathrm{~s}$, and plate reading; and performing melting curve analysis from $55^{\circ} \mathrm{C}$ to $95^{\circ} \mathrm{C}$ with reading every $0.5^{\circ} \mathrm{C}$. Fluorescence quantitative 


\section{Cellular Physiology Cell Physiol Biochem 2016;39:531-543 and Biochemistry Published online: July 07, $2016 \quad \begin{aligned} & \text { DOI: 10.1159/000445645 } 2016 \text { The Author(s). Published by S. Karger AG, Basel } \\ & \text { www.karger.com/cpb }\end{aligned}$ \\ An et al.: Terminalia Chebulanin Ameliorates Psoriasis}

PCR instrument (BIORAD, CFX-96, CA, USA) and a SYBR ${ }^{\circledR}$ Premix Ex Taq ${ }^{\mathrm{TM}}$ kit (TaKaRa) were used to detect target gene expressions, and $\beta$-actin was used as an internal reference [19]. The $2^{-\Delta \Delta \mathrm{CT}}$ method was employed to determine the relative expression of target genes normalized to $\beta$-actin, and experiments were repeated in triplicate.

\section{Western blot}

After the experiment, cells or tissues were lysed with cell lysis buffer (50 Mm Tris-HCl, pH 8.0, 150 $\mathrm{mM} \mathrm{NaCl}, 1 \%$ Triton X-100, $1 \mathrm{mM}$ EDTA, $10 \mathrm{mM} \mathrm{NaF}, 1 \mathrm{mM} \mathrm{Na}_{3} \mathrm{VO}_{4}$, and protease inhibitor cocktail) on ice for $30 \mathrm{~min}$. After centrifugation at 20,000 $\times \mathrm{g}$ for $20 \mathrm{~min}$ at $4^{\circ} \mathrm{C}$, the protein contents of supernatants were determined by BCA assay kit (Pierce, USA). After that, equal volumes of supernatants and $2 \times$ SDS loading buffer were mixed and boiled for $5 \mathrm{~min}$. Samples equal to $20 \mu \mathrm{g}$ total proteins were subjected to SDS-PAGE, transferred onto NC membranes. After blocking with 8\% non-fat milk for $1 \mathrm{~h}$ at room temperature, the membranes were incubated with indicated primary antibodies at $4{ }^{\circ} \mathrm{C}$ overnight. After washing for four times, the membranes were incubated with the appropriate horseradish peroxidase-conjugated secondary antibodies at $37^{\circ} \mathrm{C}$ for $30 \mathrm{~min}$. The protein bands were visualized using chemiluminescent reagents according to the manufacturer's instructions and quantified using Quantity One System (BIORAD, Richmond, CA).

\section{Statistical analysis}

The data were expressed as means \pm SEM. Statistical analysis were carried out by ANOVA (analysis of variance) followed by Turkey's multiple comparison tests. p value less than 0.05 was considered to be significant for all statistical tests. All the statistical analyses were performed using Graph Pad Prism statistical package.

\section{Results}

\section{TC attenuates IMQ-induced psoriatic skin lesion in mice}

To evaluate the effect of TC on psoriasis, we examined the whether TC could attenuate psoriatic skin lesion in IMQ-treated mice. After the treatment, erythema and scaling were calculated, and epidermal, ear and skinfold thickness were measured. As shown in Fig. A and $B$, the psoriasis-like skin conditions were apparent on day 2 and continued throughout the experimental period. In Control group, no psoriasis-like skin condition was observed (Fig. $1 \mathrm{~A}$ and $\mathrm{B})$. TC treatment significantly decreased erythema and scales scores in IMQ-treated mice (Fig. 1A and B). To evaluate the possible role of heme oxygenase-1 (HO-1) in TC-induced effect, ZnPP was injected in IMQ+TC-treated mice. ZnPP notably suppressed TC-induced decrease of erythema and scales score in IMQ-treated mice (Fig. 1A and B). IMQ induced a significant increase of epidermal and ear fold and skinfold thickness, compared with that of the Control group (Fig. 1C, D and E). Compared with that in IMQ group, TC markedly reduced epidermal and ear fold and skinfold thickness (Fig. 1C, D and E). In contrast, TCinduced reduction of epidermal and ear fold and skinfold thickness in IMQ-treated mice was inhibited by ZnPP. Moreover, the results of histological staining showed that IMQ resulted in acanthosis, hyperkeratosis and elongation of rete-like ridge in skin of mice (Fig. 1F). TC notably attenuated histological lesions in IMQ-treated mice (Fig. 1F). Improvement of histological lesions induced by TC was inhibited by ZnPP. The results demonstrated that TC attenuated IMQ-induced psoriatic skin lesion and HO-1 was involved in the protective effects of TC.

\section{TC inhibits M5-induced increase of proliferation in HaCaT cells}

Next, we examined the effect of TC on keratinocytes treated by M5 (a cocktail of IL-1 $\alpha$, IL-17A, IL-22, Oncostatin M and TNF $\alpha$ ). As shown in Fig. 2A, M5 cocktail-induced increase of cell proliferation in HaCaT cells was inhibited by TC treatment. In the presence of ZnPP, TCinduced decrease of cell proliferation in M5-treated HaCaT cells was markedly suppressed (Fig. 2A). mRNA expression of cyclin D1 and cyclin E was increased by M5 (Fig. 2B and C). TC treatment markedly inhibited M5-induced increase of mRNA expression of cyclin D1 
Fig. 1. Effect of TC and ZnPP on IMQ-induced psoriatic skin lesion. (A and B) On days 0,2 , 4 and 7, Psoriasis Area Severity Index (PASI) was used to assign a score of $0-4$ to each animal. (A) Erythema score $(n=8)$. (B) Scales score $(n=8)$. (C, D and E) Thickening of the skin was evaluated. (C) Epidermal thickness was measured ( $\mathrm{n}=15-20$ ). (D) Right ear fold thickness was measured on days 0 , 2, 4 and 7 ( $n=8)$. (E) Skinfold thickness on the back $(\mathrm{n}=8)$. (F) H\&E staining of the shaved back $(\mathrm{n}=8)$. Magnification $\times 200$. $^{*} \mathrm{p}$ $<0.05$, compared with Control. ** $\mathrm{p}<0.05$, compared with IMQ group. *** $\mathrm{p}<0.05$, compared with TC group.

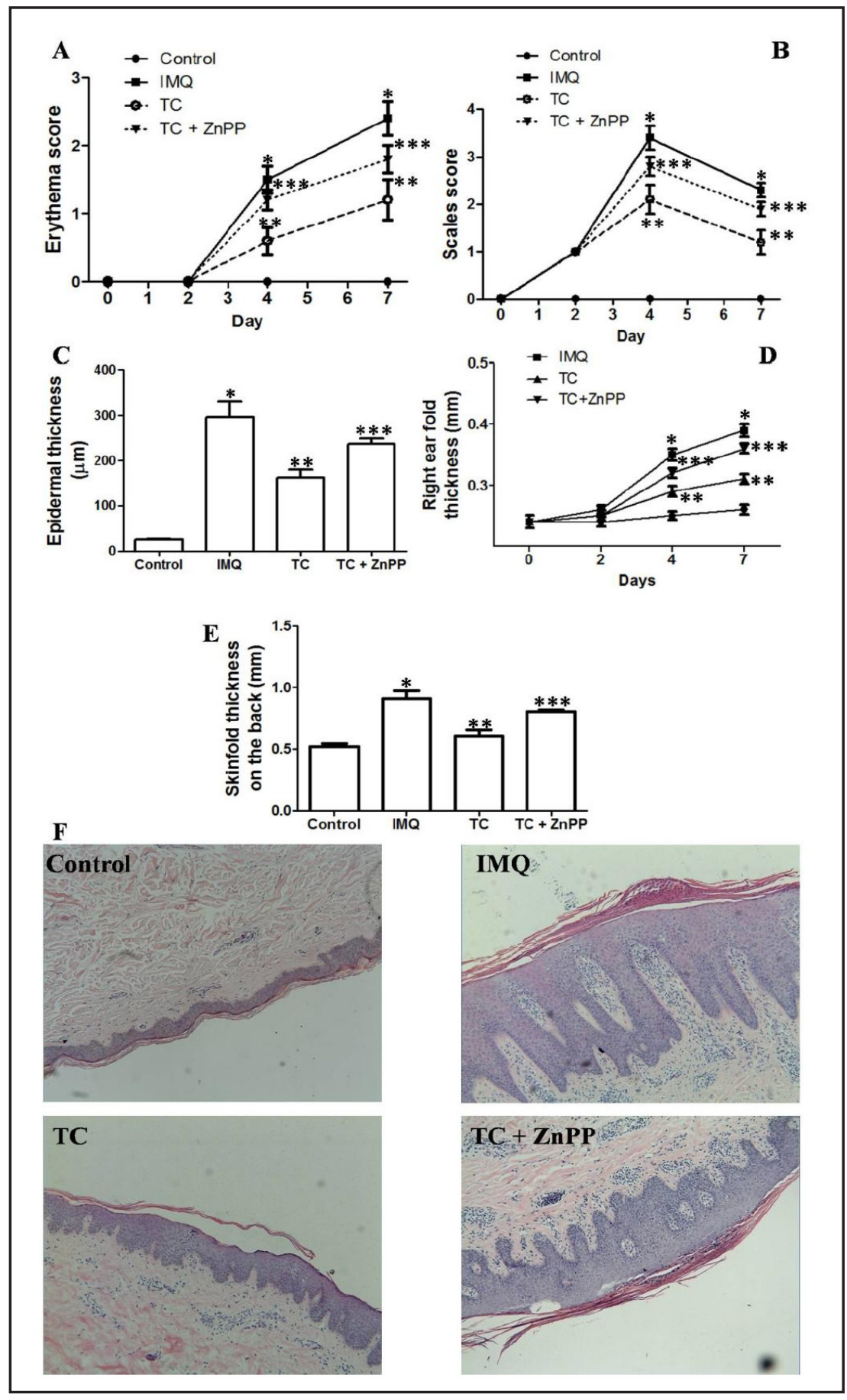

and cyclin E (Fig. 2B and C). The decrease of mRNA expression of cyclin D1 and cyclin E induced by TC in M5-treated cells were inhibited by ZnPP (Fig. 2B and C). These results demonstrated that TC inhibited M5-induced cell proliferation in HaCaT cells and the effect of TC was mediated by HO-1.

\section{TC reduces inflammation in mice and in HaCaT cells}

Systematic and local inflammation in mice and expression of proinflammatory cytokines in HaCaT cells were evaluated. As shown in Fig. 3A, B, D, E, G and H, serum and skin levels of TNF $\alpha$, IL-17A and IL-23 were dramatically increased by IMQ treatment. TC significantly inhibited IMQ-induced increase of TNF $\alpha$, IL-17A and IL-23 in serum and skin 
Fig. 2. Effect of TC and ZnPP on M5-induced increase of proliferation in HaCaT cells. HaCaT cells were exposed to $10 \mu \mathrm{g} / \mathrm{mL}$ TC for $2 \mathrm{~h}$ and then cultured with M5 for 2 days. After that, cell proliferation was measured by Cell Counting Kit-8 assay kit $(n=6)(A)$. mRNA expression of cyclin D1 (B) and cyclin E (C) was measured by real-time PCR ( $\mathrm{n}=$ 3). ${ }^{*} \mathrm{p}<0.05$, compared with Control. ${ }^{* *} \mathrm{p}<0.05$, compared with M5 group. ${ }^{* * *} \mathrm{p}<0.05$, compared with TC group.
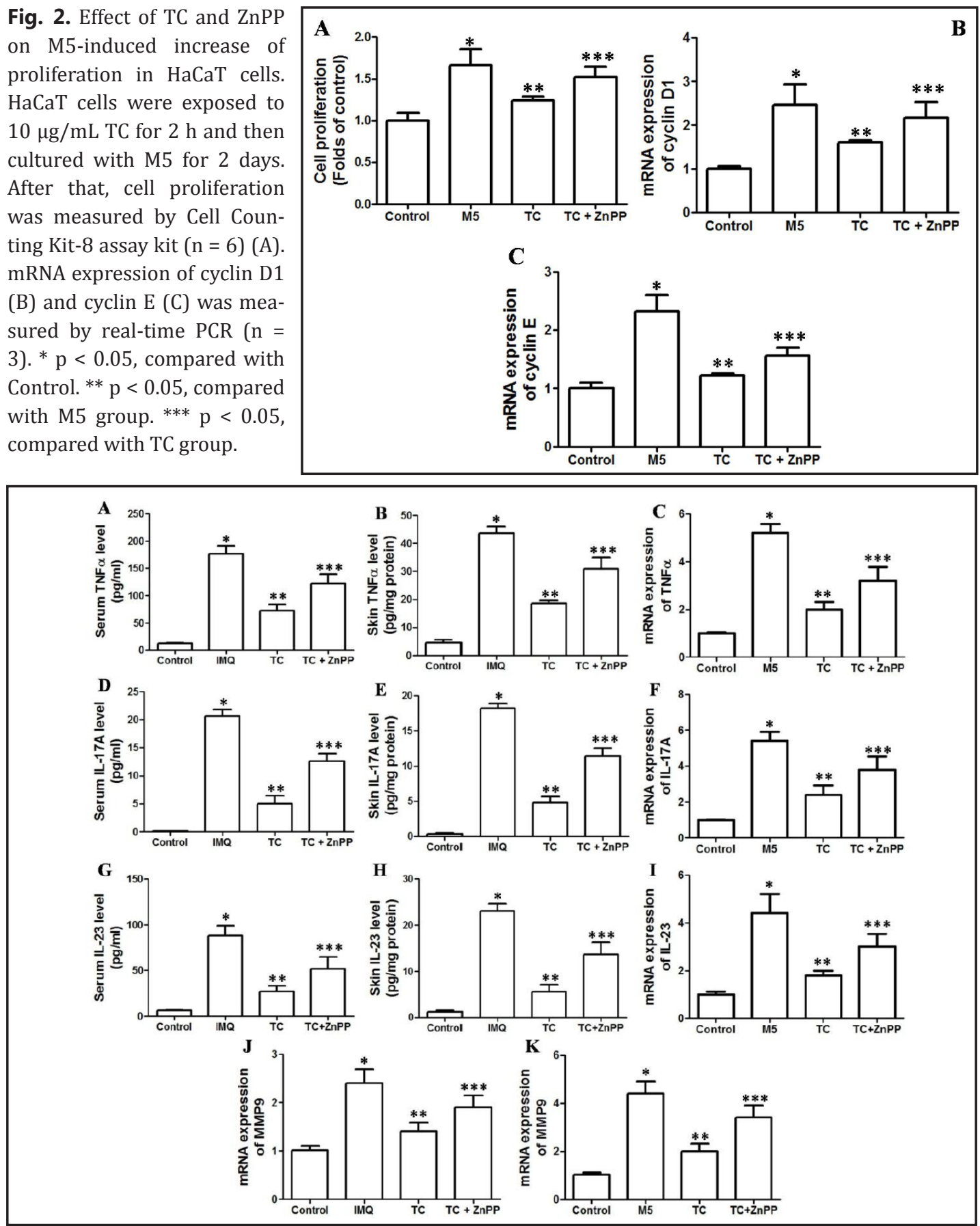

Fig. 3. Effect of TC and $\mathrm{ZnPP}$ on IMQ/M5-induced inflammation in vivo and in vitro. Serum (A, D, and G) and Skin (B, E and H) levels of TNF $\alpha$ (A and B), IL-17A (D and E), and IL-23 (G and H) were determined by ELISA kits $(n=8)$. mRNA expression of TNF $\alpha(C)$, IL-17A (F), and IL-23 (I) in HaCaT cells was determined by real-time PCR $(n=3)$. mRNA expression of MMP9 in skin tissues (J) and cells $(\mathrm{K})$ were determined by real-time PCR $(\mathrm{n}=3){ }^{*} \mathrm{p}<0.05$, compared with Control. ${ }^{* *} \mathrm{p}<0.05$, compared with IMQ or M5 group. ${ }^{* * *} \mathrm{p}$ $<0.05$, compared with TC group.

of mice (Fig. 3A, B, D, E, G and H). TC-induced decrease of TNF $\alpha$, IL-17A and IL-23 in IMQtreated mice was notably suppressed by ZnPP (Fig. 3A, B, D, E, G and H). In Fig. 3C, F and I, we showed that M5 treatment resulted in a significant increase of TNF $\alpha$, IL-17A and IL-23 


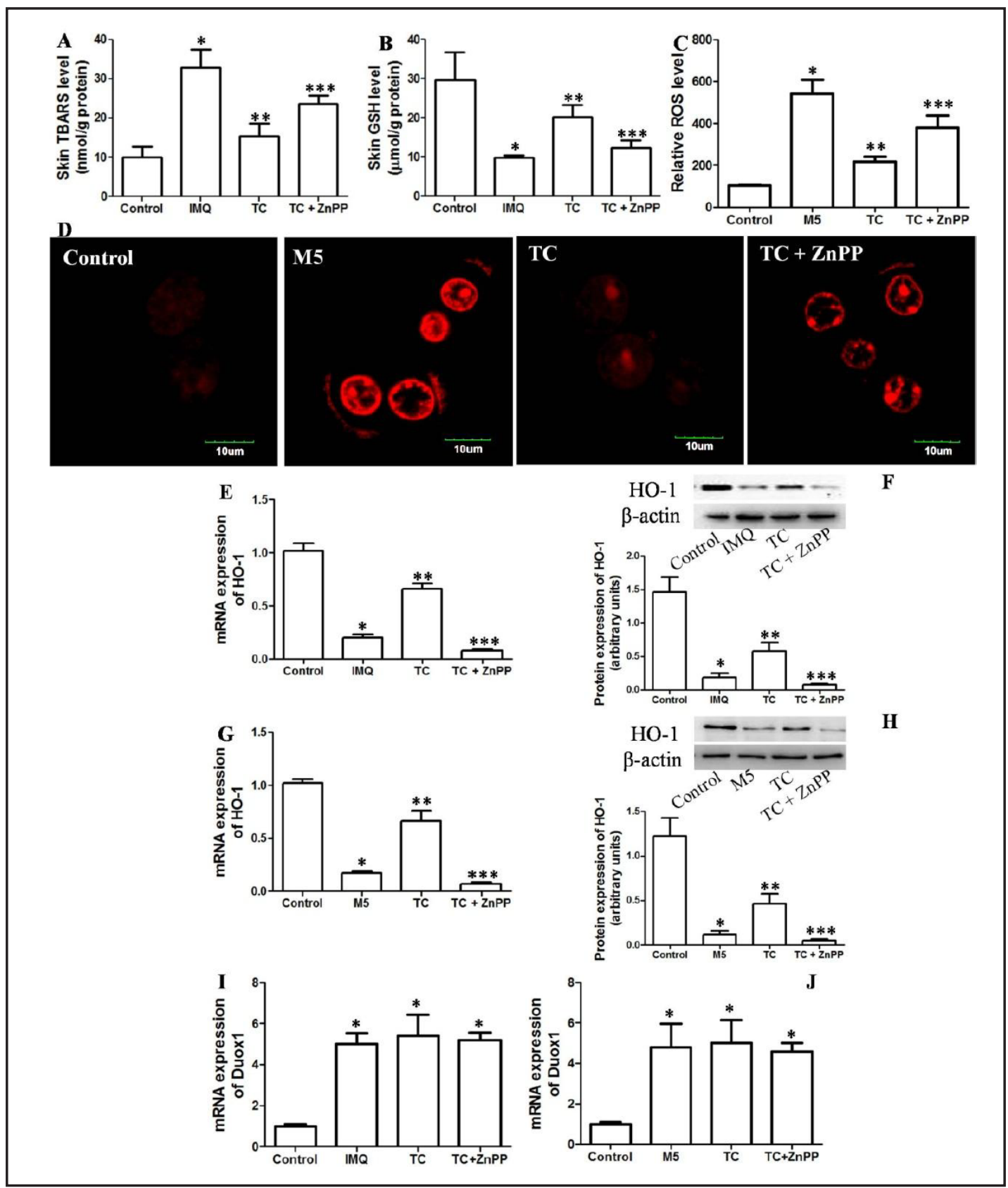

Fig. 4. Effect of TC and ZnPP on IMQ/M5-induced oxidative stress in vivo and in vitro. Skin levels of TBARS (A) and GSH (B) were determined by biochemical assay kits $(\mathrm{n}=8)$. ROS level in cells was determined by DCFH-DA staining and analyzed by flow cytometry $(C)(n=6)$, and also measured by DHE staining and observed using a confocal microscope (D) $(n=6)$. mRNA (E and G) and protein (F and H) expression of HO-1 in skin tissues (E and F) and cells ( $\mathrm{G}$ and $\mathrm{H})$ was determined by real-time PCR and western blot $(\mathrm{n}=3)$, respectively. mRNA expression of Duox1 in skin tissues (I) and cells (J) was determined by real-time PCR (n $=3$ ). ${ }^{*} \mathrm{p}<0.05$, compared with Control. ${ }^{* *} \mathrm{p}<0.05$, compared with IMQ or M5 group. ${ }^{* * *} \mathrm{p}<0.05$, compared with TC group.

expression in HaCaT cells. TC significantly inhibited M5-induced increase of TNF $\alpha$, IL-17A and IL-23 expression in HaCaT cells which was inhibited by ZnPP (Fig. 3C, F and I). Moreover, matrix metalloproteinase (MMP) 9 expression in skin tissues and cells were determined. The results showed that IMQ and M5 treatment increased MMP9 mRNA expression which 


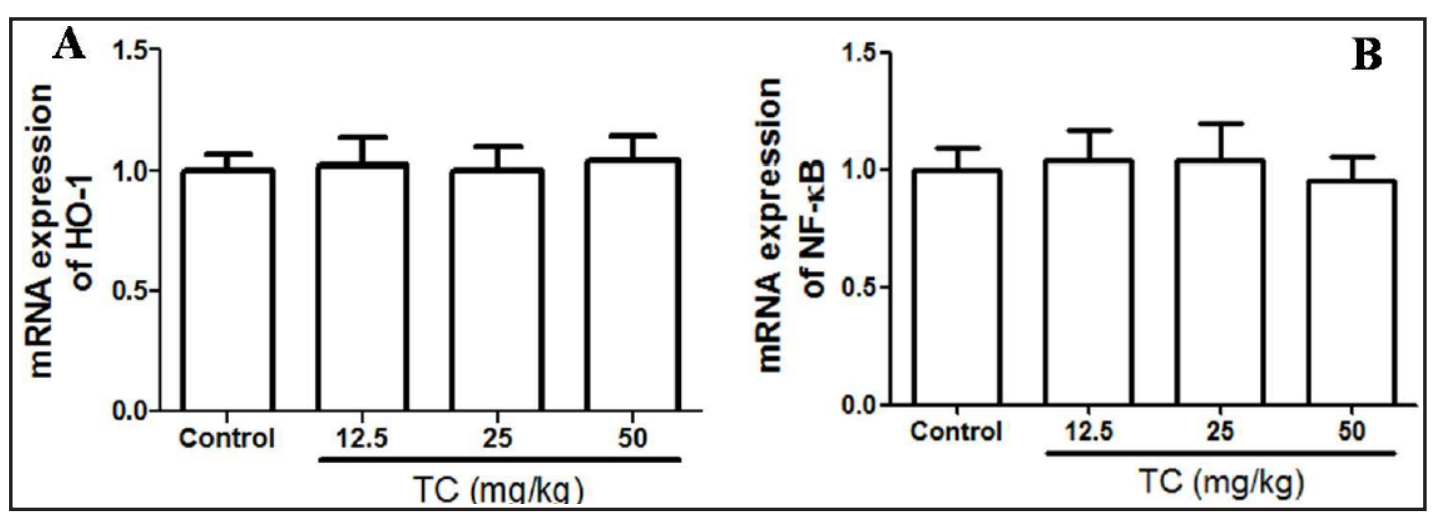

Fig. 5. Effect of TC alone on HO-1 and NF- $\kappa$ B expression in skin tissues. Mice were intragastrically administered with 12.5-50 mg/kg/day TC for a week. mRNA expression of HO-1 in skin tissues (A) and NF- $\kappa$ B (B) was determined by real-time PCR.

was significantly inhibited by TC (Fig. 3J and K). The inhibitory effect of TC on IMQ/M5induced increase of MMP9 mRNA expression was suppressed by ZnPP (Fig. 3J and K). These results demonstrated that $\mathrm{TC}$ reduced psoriatic inflammation in vivo and in vitro, which was mediated by HO-1.

\section{TC reduces oxidative stress in mice and in HaCaT cells}

The effect of TC on oxidative stress in IMQ-treated mice and M5-treated cells was assessed. IMQ increased TBARS content in skin tissue, which was inhibited by TC treatment (Fig. 4A). In the presence of ZnPP, TC-induced decrease of TBARS content was suppressed (Fig. 4A). GSH level was decreased by IMQ administration (Fig. 4B). TC treatment significantly increased GSH level in IMQ-treated mice, which was inhibited by ZnPP (Fig. 4B). Furthermore, ROS level was examined in HaCaT cells. In Fig. 4C and D, we showed that M5 induced a significant increase of ROS level. TC treatment markedly inhibited M5-induced increase of ROS generation which was suppressed by ZnPP (Fig. 4C and D). Next, we examined the expression of HO-1 in lesional skin tissues and in HaCaT cells. As shown in Fig. 4E, F G and $\mathrm{H}$, the mRNA and protein expression of HO-1 were decreased by IMQ or M5 cocktail. TC treatment significantly increased the mRNA and protein expression of HO-1 in IMQ-treated mice (Fig. 4E and F) and M5-treated cells (Fig. 4G and H). ZnPP significantly decreased the mRNA and protein expression of HO-1 to a level that was hard to detect (Fig. 4E, F G and $\mathrm{H}$ ). In our preliminary experiments, we found that TC alone had no significant effect on HO-1 expression (Fig. 5A). The results indicated that inhibition of the decrease of HO-1 rather than induction of HO-1 was involved in the anti-psoriatic of TC. The administration of ZnPP and cobalt protoporphyrin (CoPP), an inducer of HO-1, could significantly decrease or increase HO-1 protein expression in normal animals (Fig. 6A). To confirm the protective role of HO-1 induction against psoriatic lesions, we examined the effect of CoPP on IMQinduced right ear fold and skinfold thickness. As shown in Fig. 6B and C, CoPP significantly decreased right ear fold and skinfold thickness in IMQ-treated mice, indicating that HO-1 induction protected against psoriatic lesions. However, TC-induced decrease of right ear fold and skinfold thickness was more evident than that of CoPP in IMQ-treated mice. The results demonstrated that in addition to the regulation of HO-1, other signaling pathways may also be involved in the anti-psoriatic of TC.

Moreover, we tried to explore the source of ROS generation through determination of the expression of several members of NADPH oxidases (NOX) family. We found that IMQ and M5 cocktail resulted in a significant increase in Duox1 (Fig. 4I and J), but had no significant effect on NOX4 and Duox2 (data not shown). TC and ZnPP treatment did not significantly affect Duox1 expression in mice and in cells (Fig. 4I and J). These results demonstrated that TC reduced oxidative stress under psoriatic condition and HO-1-mediated elimination of ROS (not production of ROS) was involved in the anti-oxidative effect of TC. 


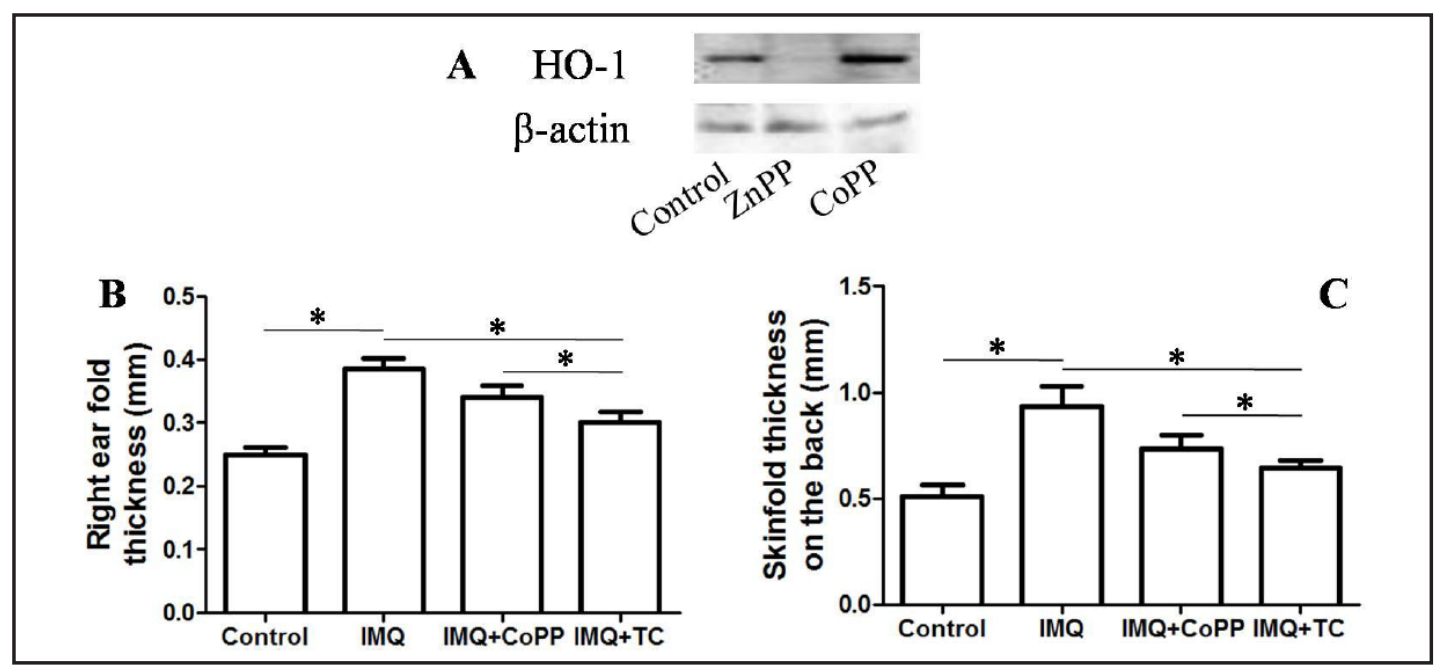

Fig. 6. Effect of CoPP on IMQ-induced psoriatic lesions. A. Mice were injected with $10 \mathrm{mg} / \mathrm{kg} \mathrm{ZnPP}$ or CoPP for a week and then skin protein expression of HO-1 was examined by western blot. B and C. Mice were treated by IMQ with or without CoPP (10 mg/kg/day) or TC administration (50 mg/kg/day) for a week. Right ear fold thickness and Skinfold thickness were measured. ${ }^{*} \mathrm{p}<0.05$.

\section{HO-1-mediated inhibition of $\mathrm{NF- \kappa B}$ is involved in TC-induced anti-psoriatic effect}

In the next step, we examined the mechanism underlying HO-1-mediated anti-psoriatic effect of TC. The effect of TC and ZnPP on P65 NF- $\kappa$ B expression in mice and in HaCaT cells was determined. As shown in Fig. 7A-D, IMQ and M5 cocktail resulted in a significant increase in mRNA and protein expression of p65 NF- $\kappa B$ (Fig. 7A-D). TC significantly inhibited the increase of p65 NF- $\kappa$ B expression in tissues and cells (Fig. 7A-D). The inhibitory effect of TC on p65 NF- $\mathrm{kB}$ expression was notably suppressed by ZnPP (Fig. 7A-D). In our preliminary experiments, we found that TC alone had no significant effect on p65 NF- $\kappa B$ expression (Fig. $7 \mathrm{~B}$ ), indicating that the effect of TC on NF- $\mathrm{BB}$ expression was mediated by regulation of $\mathrm{HO}-$ 1. To examine the possible role of inhibition of p65 NF- $\kappa \mathrm{B}$ in the anti-psoriatic effect of TC, cells were transfected with $\mathrm{p} 65 \mathrm{NF}-\kappa \mathrm{B}$ plasmids. The results showed that overexpression of p65 NF- $\kappa$ B notably inhibited TC-induced decrease of TNF $\alpha$, IL-17A, and IL-23 expression and cell proliferation in M5-treated HaCaT cells (Fig. 7E-H). The results demonstrated that HO1-mediated downregulation of $\mathrm{p} 65 \mathrm{NF}-\mathrm{\kappa B}$ was responsible for the anti-psoriatic effect of TC.

\section{Discussion}

Severe inflammation, oxidative stress, and poorly-differentiated, hyperproliferative keratinocytes are the hallmarks of psoriasis [22, 23]. In response to psoriatic stimuli, expression of pro-inflammatory cytokines and chemokines is increased, attracting immune cells to local position $[5,24]$. Lymphocytes are activated, migrate to the local skin and secrete pro-inflammatory cytokines, including IFN- $\gamma$, IL-17A, IL-17F, IL-22, and IL-23, resulting in uncontrolled inflammation and keratinocyte hyperproliferation [5, 25]. Enhancement of keratinocyte hyperproliferation produces more proinflammatory cytokines [26-28]. ROS could activate various pathways that mediate inflammation under psoriatic condition [23]. TC is a polyphenolic compound that was found to possess antioxidant and anti-inflammatory activities [16,17].

In our study, we examined the anti-psoriatic effect of TC in vivo and in vitro. The results showed that TC exhibited potent anti-psoriatic activities, as evidenced by improvement of IMQ-induced epidermal, ear fold and skinfold thickening, improved erythema and scaling scores and histological lesions in IMQ-treated mice, and inhibition of M5-induced keratinocyte proliferation. TC treatment attenuated psoriatic inflammation in mice treated 

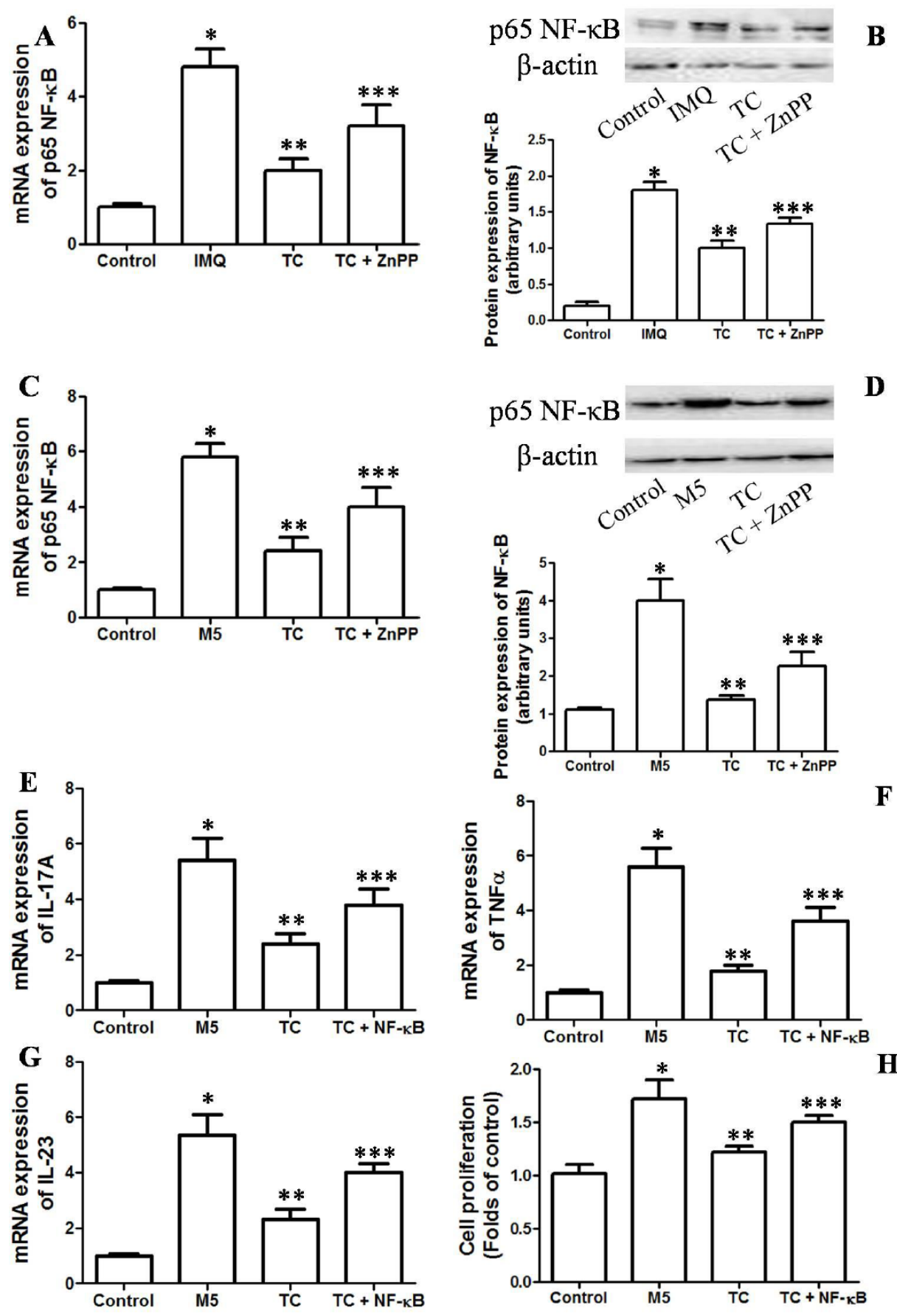

Fig. 7. Role of inhibition of NF- $\kappa B$ in the protective effect of TC against psoriatic inflammation. mRNA (A and $C$ ) and protein (B and D) expression of p65 NF- $\kappa$ B in skin tissues (A and B) and cells (C and D) was determined by real-time PCR and western blot $(n=3)$, respectively. HaCaT cells were transfected with NF$\kappa B$ plasmids, incubated with $10 \mu \mathrm{g} / \mathrm{mL}$ TC for $2 \mathrm{~h}$ and then exposed to M5 for 2 days. After that, mRNA expression of IL-17A (E), TNF $\alpha(F)$ and IL-23 (G) was determined by real-time PCR $(n=3)$. Cell proliferation was determined by Cell Counting Kit-8 assay kit $(\mathrm{n}=6)(\mathrm{H}){ }^{*} \mathrm{p}<0.05$, compared with Control. ${ }^{* *} \mathrm{p}<0.05$, compared with IMQ or M5 group. ${ }^{* * *} \mathrm{p}<0.05$, compared with TC group.

by IMQ and in cells treated by M5, as reflected by decrease of TNF $\alpha$, IL-17A and IL-23. IMQ model is strongly dependent on the IL-23/STAT3/Th17 pathway [29]. We suggested that TC- 


\section{Cellular Physiology Cell Physiol Biochem 2016;39:531-543 \begin{tabular}{l|l} 
DOI: 10.1159/000445645 & $\begin{array}{l}\text { O 2016 The Author(s). Published by S. Karger AG, Basel } \\
\text { wwww.karger.com/cpb }\end{array}$
\end{tabular} \\ An et al.: Terminalia Chebulanin Ameliorates Psoriasis}

induced regulation of IL-23 pathway played a role in its anti-psoriatic effect. Moreover, TC inhibited the expression of MMP9 through HO-1 in mice and in cells. MMP-9 plays important roles in both skin remodeling and disease in chemically-induced inflammation [30]. A previous study showed that Terminalia chebula Retzius could affect MMP9 expression and reduce 2,4-dinitrofluorobenzene-induced atopic dermatitis [31]. The results indicated that the amelioration of inflammatory response mediated the protective effect of TC and its derivatives against psoriatic skin lesion and atopic dermatitis.

TC treatment also decreased TBARS content and increased GSH content in IMQ-treated mice, and decreased ROS level in M5-treated cells, indicating that oxidative stress under psoriatic condition was inhibited by TC. HO is the rate-limiting enzyme for degradation of heme [32]. Large amount of evidence has shown that HO plays an important in cellular protection against inflammation and oxidative stress [33-37]. HO-1 is an inducible isoform of HO, which plays an important role in skin injury and wound healing. Moreover, HO-1 expression is associated with epidermal differentiation in normal skin and HO-1 induction attenuates IMQ-induced psoriatic inflammation [38]. In our study, we focused on the possible role of HO-1 in the anti-psoriatic effect of TC. We showed that TC inhibited the decrease of HO-1 expression in IMQ-treated mice and M5-treated cells. ZnPP, an inhibitor of HO-1, could inhibit all those effects of TC on psoriatic lesional skin, inflammation, oxidative stress and keratinocytes proliferation. The results demonstrated that HO-1 was responsible for the anti-psoriatic effect of TC.

$\mathrm{NF}-\kappa \mathrm{B}$ is a key determinant in the development of psoriasis through regulation of various proinflammatory cytokines $[39,40]$. In the present study, we also examined the possible role of NF- $\mathrm{B}$ in anti-psoriatic effect of TC. We showed that TC suppressed the increase of p65 $\mathrm{NF}-\kappa \mathrm{B}$ expression under psoriatic condition. Since ZnPP suppressed TC-induced decrease of p65 NF- $\kappa \mathrm{B}$ expression, HO-1 was involved in the regulation of NF- $\kappa \mathrm{B}$ induced by TC. Moreover, downregulation of NF- $\kappa \mathrm{B}$ was involved in TC-induced anti-psoriatic effect of TC, as illustrated by the inhibition of TC-induced decrease of the expression of proinflammatory cytokines and keratinocytes proliferation induced by overexpression of NF- $\kappa \mathrm{B}$.

As the effects of TC are not strong enough to completely eliminate skin lesions, TCbased products may be used in mild psoriasis cases or perhaps as a combination therapy. In future study, we will test the effect of long-term use of TC and we expect to obtain more convincing data. In conclusion, in the present study, we found that TC attenuated IMQ-induced psoriatic skin lesion in mice and reduced M5-induced proliferation and inflammation in keratinocytes. HO-1 was responsible for the anti-psoriatic effect of TC through inhibition of oxidative stress and downregulation of NF- $\kappa B$ and the subsequent inhibition of inflammation and keratinocytes proliferation. The data demonstrated that TC exhibited protective effect through the inhibition of the decrease of HO-1 expression rather than induction of HO-1 expression. Further studies are needed to examine the exact mechanism underlying TCinduced regulation of HO-1 and HO-1-meidated regulation of NF- $\kappa$ B. Overall, the data provide a novel potential therapeutic option for psoriasis.

\section{Disclosure Statement}

The authors declare that there are none conflict of interest.

\section{References}

1 Crow JM: Psoriasis uncovered. Nature 2012;492:S50-S51.

2 Harden JL, Krueger JG, Bowcock AM: The immunogenetics of Psoriasis: A comprehensive review. J Autoimmun 2015;64:66-73.

3 Lonnberg AS, Skov L, Duffy DL, Skytthe A, Kyvik KO, Pedersen OB, Thomsen SF: Genetic factors explain variation in the age at onset of psoriasis: A population-based twin study. Acta Derm Venereol 2016;96:3538. 


\section{Cellular Physiology Cell Physiol Biochem 2016;39:531-543 \begin{tabular}{l|l|l|}
\hline DOI: 10.1159/000445645 & $\begin{array}{l}\text { C) 2016 The Author(s). Published by S. Karger AG, Basel } \\
\text { www.karger.com/cpb }\end{array}$
\end{tabular} \\ An et al.: Terminalia Chebulanin Ameliorates Psoriasis}

4 Park BS, Youn JI: Factors influencing psoriasis: An analysis based upon the extent of involvement and clinical type. J Dermatol 1998;25:97-102.

$5 \quad$ Perera GK, Di Meglio P, Nestle FO: Psoriasis. Annu Rev Pathol 2012;7:385-422.

6 Zhang Y, Tu C, Zhang D, Zheng Y, Peng Z, Feng Y, Xiao S, Li Z: Wnt/beta-Catenin and Wnt5a/Ca pathways regulate proliferation and apoptosis of keratinocytes in psoriasis lesions. Cell Physiol Biochem 2015;36:1890-1902.

7 Griffiths CE, Barker JN: Pathogenesis and clinical features of psoriasis. Lancet 2007;370:263-271.

8 Gottlieb AB, Armstrong AW: Psoriasis outcome measures: A report from the GRAPPA 2012 annual meeting. J Rheumatol 2013;40:1428-1433.

9 Cohen AD, Sherf M, Vidavsky L, Vardy DA, Shapiro J, Meyerovitch J: Association between psoriasis and the metabolic syndrome. A cross-sectional study. Dermatology 2008;216:152-155.

10 Neimann AL, Shin DB, Wang X, Margolis DJ, Troxel AB, Gelfand JM: Prevalence of cardiovascular risk factors in patients with psoriasis. J Am Acad Dermatol 2006;55:829-835.

11 Kastelan M, Prpic-Massari L, Brajac I: Apoptosis in psoriasis. Acta Dermatovenerol Croat 2009;17:182-186.

12 Lee HS, Won NH, Kim KH, Lee H, Jun W, Lee KW: Antioxidant effects of aqueous extract of Terminalia chebula in vivo and in vitro. Biol Pharm Bull 2005;28:1639-1644.

13 Das ND, Jung KH, Park JH, Mondol MA, Shin HJ, Lee HS, Park KS, Choi MR, Kim KS, Kim MS, Lee SR, Chai YG: Terminalia chebula extract acts as a potential NF-kappaB inhibitor in human lymphoblastic T cells. Phytother Res 2011;25:927-934.

14 Lee WJ, Moon JS, Kim SI, Kim YT, Nash O, Bahn YS, Kim SU: Inhibition of the calcineurin pathway by two tannins, chebulagic acid and chebulanin, isolated from Harrisonia abyssinica Oliv. J Microbiol Biotechnol 2014;24:1377-1381.

15 Liu M, Katerere DR, Gray AI, Seidel V: Phytochemical and antifungal studies on Terminalia mollis and Terminalia brachystemma. Fitoterapia 2009;80:369-373.

16 Zhao Y, Liu F, Liu Y, Zhou D, Dai Q, Liu S: Anti-Arthritic Effect of Chebulanin on Collagen-Induced Arthritis in Mice. Plos One 2015;10:e139052.

17 Majed F, Nafees S, Rashid S, Ali N, Hasan SK, Ali R, Shahid A, Sultana S: Terminalia chebula attenuates DMBA/Croton Oil-Induced oxidative stress and inflammation in swiss albino mouse skin. Toxicol Int 2015;22:21-29.

18 Nadeem A, Al-Harbi NO, Al-Harbi MM, El-Sherbeeny AM, Ahmad SF, Siddiqui N, Ansari MA, Zoheir KM, Attia SM, Al-Hosaini KA, Al-Sharary SD: Imiquimod-induced psoriasis-like skin inflammation is suppressed by BET bromodomain inhibitor in mice through RORC/IL-17A pathway modulation. Pharmacol Res 2015;99:248-257.

19 An J, Li Z, Dong Y, Ren J, Huo J: Amentoflavone protects against psoriasis-like skin lesion through suppression of NF-kappaB-mediated inflammation and keratinocyte proliferation. Mol Cell Biochem 2016;413:87-95.

20 Zhou J, Gao Y, Yi X, Ding Y: Ginsenoside rh2 suppresses neovascularization in xenograft psoriasis model. Cell Physiol Biochem 2015;36:980-987.

21 Zhao Y, Sun J, Dou W, Hu JH: Curcumin inhibits proliferation of interleukin-22-treated HaCaT cells. Int J Clin Exp Med 2015;8:9580-9584.

22 Nograles KE, Davidovici B, Krueger JG: New insights in the immunologic basis of psoriasis. Semin Cutan Med Surg 2010;29:3-9.

23 Zhou Q Mrowietz U, Rostami-Yazdi M: Oxidative stress in the pathogenesis of psoriasis. Free Radical Bio Med 2009;47:891-905.

24 Xiong H, Xu Y, Tan G, Han Y, Tang Z, Xu W, Zeng F, Guo Q: Glycyrrhizin ameliorates imiquimod-induced psoriasis-like skin lesions in BALB/c mice and inhibits TNF-alpha-induced ICAM-1 expression via NFkappaB/MAPK in HaCaT cells. Cell Physiol Biochem 2015;35:1335-1346.

25 Nestle FO, Kaplan DH, Barker J: Psoriasis. N Engl J Med 2009;361:496-509.

26 Grine L, Dejager L, Libert C, Vandenbroucke RE: An inflammatory triangle in psoriasis: TNF, type I IFNs and IL-17. Cytokine Growth Factor Rev 2015;26:25-33.

27 Wagner EF, Schonthaler HB, Guinea-Viniegra J, Tschachler E: Psoriasis: What we have learned from mouse models. Nat Rev Rheumatol 2010;6:704-714.

28 Schon MP, Boehncke WH: Psoriasis. N Engl J Med 2005;352:1899-1912. 


\section{Cellular Physiology Cell Physiol Biochem 2016;39:531-543 \begin{tabular}{l|l|l} 
DOI: 10.1159/000445645 & $\begin{array}{l}\text { O 2016 The Author(s). Published by S. Karger AG, Basel } \\
\text { www.karger.com/cpb }\end{array}$
\end{tabular}

29 Harden JL, Krueger JG, Bowcock AM: The immunogenetics of Psoriasis: A comprehensive review. J Autoimmun 2015;64:66-73.

30 Parks WC, Wilson CL, Lopez-Boado YS: Matrix metalloproteinases as modulators of inflammation and innate immunity. Nat Rev Immunol 2004;4:617-629.

31 Nam DY, Lee JM, Heo JC, Lee SH: Mitigation of 2,4-dinitrofluorobenzene-induced atopic dermatitis-related symptoms by Terminalia chebula Retzius. Int J Mol Med 2011;28:1013-1018.

32 Kang X, Kong F, Wu X, Ren Y, Wu S, Wu K, Jiang Z, Zhang W: High glucose promotes tumor invasion and increases metastasis-associated protein expression in human lung epithelial cells by upregulating heme oxygenase-1 via reactive oxygen species or the TGF-beta1/PI3K/Akt signaling pathway. Cell Physiol Biochem 2015;35:1008-1022.

33 Alcaraz MJ, Fernandez P, Guillen MI: Anti-inflammatory actions of the heme oxygenase-1 pathway. Curr Pharm Des 2003;9:2541-2551.

34 Han F, Guo Y, Xu L, Hou N, Han F, Sun X: Induction of haemeoxygenase-1 directly improves endothelial function in isolated aortas from obese rats through the Ampk-Pi3k/Akt-Enos pathway. Cell Physiol Biochem 2015;36:1480-1490.

35 Liu XH, Wang XL, Xin H, Wu D, Xin XM, Miao L, Zhang QY, Zhou Y, Liu Q, Zhang Q, Zhu YZ: Induction of heme oxygenase-1 by sodium 9-Hydroxyltanshinone IIA sulfonate derivative contributes to inhibit LPS-Mediated inflammatory response in macrophages. Cell Physiol Biochem 2015;36:1316-1330.

36 Han F, Hui Z, Zhang S, Hou N, Wang Y, Sun X: Induction of haemeoxygenase-1 improves FFA-induced endothelial dysfunction in rat aorta. Cell Physiol Biochem 2015;35:1230-1240.

37 Ursu ON, Sauter M, Ettischer N, Kandolf R, Klingel K: Heme oxygenase-1 mediates oxidative stress and apoptosis in coxsackievirus B3-induced myocarditis. Cell Physiol Biochem 2014;33:52-66.

38 Zhang B, Xie S, Su Z, Song S, Xu H, Chen G, Cao W, Yin S, Gao Q Wang H: Heme oxygenase-1 induction attenuates imiquimod-induced psoriasiform inflammation by negative regulation of Stat3 signaling. Sci Rep 2016;6:21132.

39 Yan S, Xu Z, Lou F, Zhang L, Ke F, Bai J, Liu Z, Liu J, Wang H, Zhu H, Sun Y, Cai W, Gao Y, Su B, Li Q Yang X, Yu J, Lai Y, Yu XZ, Zheng Y, Shen N, Chin YE, Wang H: NF-kappaB-induced microRNA-31 promotes epidermal hyperplasia by repressing protein phosphatase 6 in psoriasis. Nat Commun 2015;6:7652.

40 Hong KK, Gwak MJ, Song J, Kim NI: NF-kappaB pathway activation and PTEN downregulation in psoriasis. Br J Dermatol 2015; 174:433-435. 